\title{
ON THE EFFECT OF LIGATURE OF ONE URETER.
}

\author{
By Miss B. Sheldon Amos. \\ From the Porte Vieux Laboratory, Alexandria (Sonitary, Maritime, and Qnarantine \\ Conuncil of Egypt).
}

\section{(Plate XXII.)}

THE effects following on the ligature of both ureters are well known, but it is only lately that the effect of the ligature of one ureter on both kidneys and on other organs has attracted attention.

Nefedieff, after ligature of one ureter in the rabbit, described changes resembling those found in human beings suffering from chronic nephritis, namely: hyperæmia of the heart, stasis of the blood in the liver and spleen, and alterations in the kidney on the non-operated side. $\mathrm{He}$ also found that the serum of such an animal was nephrotoxic for other rabbits. He concluded that there was a progressive accumulation of toxic substances in the body. Further, as the epithelium cells of the tied kidney were atrophied, the nuclei of the cells degenerated, and the epithelium of the collecting tubes atrophied, he concluded that the ligature "enabled certain specific substances (cytotoxins) previously contained in the kidney cells" to escape, enter the general circulation, and act as nephrotoxins. In his opinion this toxic action might also be due to the retention within the organism of certain substances which ought to be completely eliminated, and some of which might have a specific action on the kidneys.

I am not in accord with Nefedieff, for my experiments of ligaturing the kidney on one side did not reveal any specific lesions of the other kidney, nor has injection of rabbit kidney substance into rabbits shown that such kidney substance was toxic for rabbits.

Albarran, criticising these experiments, objected that if a cytotoxic serum could be produced by ligaturing one ureter, it must be nephrotoxic, not only for the kidneys of other animals but also for the other kidney of the same animal. Albarran maintained that in the protocol of Nefedieff's experiments, the second kidney was stated to be uninjured at a time when the serum had already nephrotoxic properties. This objection of Albarran is valid.

Albarran and Bernard denierl that a ligatured kidney ever produced specific cytotoxic nephrotoxins, and based their conclusions on the following experimental facts :-

1. They injected guinea-pig kidneys into rabbits, and found that, though the injected animal succumbed more or less rapidly, the kidney lesions were unimportant. (Castaigne and Rathery had similar results.) Moreover, the liver of the injected animals was as much injured as the kidneys, and showed slight degeneration. When several injections were made before death, both 
liver and kidneys were somewhat more markedly injured, namely, their cells were degenerated, the protoplasm being no longer granular but clear.

2. They injected rabbits with guinea-pig liver and produced precisely similar lesions in both liver and kidney.

3. They prepared rabbit serum by injection of both guinea-pig kidney and guinea-pig liver, and found with each that, though death supervened in the subsequently injected guinea-pigs, the kidneys were slightly and similarly affected; there being a slight cellular vacuolisation. Rather more definite results were obtained by injecting guinea-pig kidney into ducks, and using the serum of the latter animals; yet even then a very large dose of the serum was necessary to produce a noticeable alteration in the kidney of the injected animal ; here again the liver was similarly degenerated.

4. They ligatured one ureter in several rabbits, and in each case, twentyone days after, they found the opposite kidney remained healthy and the serum injected into other animals produced either no kidney lesions or only very insignificant ones. With animals whose serum they took forty-one days after the ligature, however, contradictory results were obtained. In one case profound kidney lesions were found in the non-ligatured kidney, and in the kidneys of the animal injected with its serum; in another case there were no such lesions.

In considering these facts, Albarran and Bernard concluded that by none of these methods can it be demonstrated that there are renal cytotoxins with a specific affinity for renal cells.

It will be seen that the experiments here related lead to very similar conclusions.

Pearce has made the following clear statement as the result of his researches:- "Ligature of the ureter or vessels of one kidney does not produce changes which differ in any way from those which follow unilateral nephrectomy. Four changes occur-loss of weight, slight intermittent albuminuria and hyperplasia of the opposite kidney, associated as a rule with increased granulation of renal cells. He examined the causes of the changes mentioned, and considers, first, the increased function of the remaining kidney, and, secondly, the elimination by the remaining kidney of the products of the destruction of the ligatured kidney.

If the products of the latter were directly injurious we should expect graver changes in the opposite kidney than in the case of nephrectomised animals. As such is not the case, we are forced to the conclusion that increased function is responsible for the changes observed, and that the products of the dissolution of one kidney exert no directly deleterious action on the opposite kidney. In other words, under normal physiological conditions, degeneration of renal cells does not lead to the production of autonephrotoxins.

Pearce, moreover, controverts the statement of Albarran and Bernard that kidney tissue is lethal, and attributes the mortality among their animals entirely to bacterial infection. According to him injections of all kinds of animal tissues also produce slight renal lesions, described by Castaigne and lathery as specific lesions, namely, loss of granulation in the protoplasm of the convoluted tubes and actual disintegration of protoplasm.

In the literature of the subject we find no evidence of lesions of the liver in animals with one ureter ligatured except in Guyon's 
and Albarran's paper; they mention that small hæmorrhages may be present in the liver (this we have not found); and, further, Ebstein states that after the ligature of the ureter in a cock, or after progressive renal destruction by repeated subcutaneous injections of uric acid, "there is uratic impregnation of all the tissues, and foci of necrosis around uratic infarcts are disseminated in the liver."

Castaigne and Rathery mention liver changes.

Ebstein's facts would support the view that ligature of the ureters causes deposit of foreign substances.

\section{Personal Observations; the Effect of the Ligature of ONE URETER.}

I have tied one ureter in six guinea-pigs and ten rabbits, and both ureters in two rabbits, for purposes of comparison.

The procedure for ligature has been the same in all the animals. When fully anæsthetised with ether, the animal was extended on the back, and its abdominal surface well disinfected with sublimate solution; the lower half of the abdomen and the groins were then carefully shaved and again washed with sublimate solution. The abdomen was opened in the middle line, from a point at about the middle of its length down to the pubes. The peritoneum was opened (on a director). The intestines were then pushed aside, and the ureter, lying on the psoas muscle, was picked up and (usually) ligatured twice close together with silk, and then cut through between the ligatures. In some cases only one ligature was applied and the ureter was not cut through. The peritoneum, muscular coat, and skin were then stitched up in successive layers, and a dressing of iodoform and collodion applied. The animals recovered speedily from the operation, but the ultimate behaviour was different in guinea-pigs from that in rabbits. Guinea-pigs are less resistant to this operation.

Of the six guinea-pigs, one lived 5 days, one lived 20 days, four lived 23 days - an average of $19 \frac{1}{2}$ days. Whereas of the eight rabbits in which one ureter was tied and the animal left to die, one lived 28 days, one 29 , one 53, and one 55 days; one lived 63 days, one 79 days, one 100 days, and one 130 days-an average of 52 days. The other three rabbits were killed in 2 days, 15 days, and 29 days respectively. Where both ureters were tied, the animal lived 2 days.

At first the animals seem perfectly well; they eat well and pass urine normally, which is neither albuminous nor scanty. A few days before death they begin to look ill and sit huddled up, lose appetite, and cease to pass urine. Two of the rabbits were seen to have convulsions for some hours before death, and in these two there was distinct Cheyne-Stokes breathing; their whole condition suggested uræmic coma. I did not observe the exact mode of death in the other animals.

The following generalisations may be made from the post-mortem and microscopic examinations of the organs; both species of animal are considered together.

\section{Macroscopic Examination.}

1. The tied ureter was dilated, to a greater or less extent, and in two cases (guinea-pigs 3 and 5) contained pus. 
2. The kidney on the tied side is always somewhat dilated by contained urine (guinea-pigs $1,2,4,5,6$ ), and sometimes enormously so (rabbits $1,2,3,4$ ); in two cases (guinea-pigs 3,5 ) there was pus in the pelvis of the kidney. As a rule, very enlarged veins were seen coming from the ligatured kidney.

3. The kidncy on the control side was apparently slightly enlarged and in some cases congested; but in three of the guinea-pigs it did not seem to be affected macroscopically.

4. The suprarenal capsulcs were congested and large in most of the guinea-pigs $(1,2,3,4,5,6)$, but were not visibly affected in any of the rabbits. In only one guinea-pig (6) was the suprarenal of the ticel kidney more congested than that of the control kidney.

5. The liver was visibly congested in all the subjects except one (guinea-pig 4).

The other organs were normal. Only one animal was found to be otherwise diseased, c.g. a rabbit which was infected with coccidia.

\section{Microscopic Examination.}

The condition of the kidneys on the tied side has already been described by Castaigne and Rathery, Pierce, and Nefedieff, and here I shall give merely a résumé of the changes as seen in these animals at varying dates after operation.

So soon as five days after operation we see slight atrophic changes in the tubes and hyperæmia; the gland cells in the tubes are breaking up; but there is no inflammatory infiltration by round cells or connective' tissue cells in or among the tubes.

In those guinea-pigs which lived for twenty to twenty-three days there is much inflammatory change; e.g. hyperæmia, swelling, and infiltration by round cells and by connective tissue cells. Among the guinea-pigs there is no definite comparative relation between the number of days of life and the amount of cirrhosis and destruction of kidney substance; e.g. guinea-pig 5 only lived twenty-two days, but the kidney cortex is much more cirrhosed, and round-celled infiltration and thickening of the glomerular capsules is more marked than in the other guinea-pigs which lived twenty-three days. In the rabbits, in which life was much longer, the changes are most marked in those that lived longest.

In both rabbits and guinea-pigs we find all the kidney structures, with one exception, generally affected: though the first, and the most, to suffer are the conducting tubules and convoluted (secreting) tubules, and last and least the glomeruli and their capsules and the intertubular spaces. The glomerular spaces are not affected in the guinenpig. The epithelium of the convoluted tubules loses its peculiar striated effect, swells, and then breaks down; the protoplasm is then shed piecemeal into the lumen of the tube. There is no doubt that the cells sometimes extrude their protoplasm in the form of a ball, for 
we can see the process in all stages (Plate XXII. Figs. 1, 2, 3, 5); the inner edge of the cell begins to "swell up" and to become globular and paler, and finally it is extruded out of the cell. Many of these balls may be seen lying in a tube lumen (Plate XXII. Fig. 2).

None of these granular protoplasmic balls are to be seen in the guinea-pig kidueys, nor in those rabbits that lived for more than two lays. One may suppose that this phenomenon only occurs early in the process of degeneration, while the cell has still strength to struggle against (possibly) diseased elements. And as it is not found in the long tubes in the hilus, I conclude that they are finally welded together into casts (Plate XXII. Figs. 6, 7, 8).

In some of these kidneys there is fatty degeneration, involving at first the protoplasm of the cells (Plate XXII. Fig. $3, a, d$ ) and later the nuclei as well.

Blood casts in the secreting tubes are but rarely to be seen.

Where there is much intertubular connective tissue, the cells of the tubules are pressed together (Plate XXII. Figs. 6 and 7), and the tubes are so crushed that they are no longer recognisable as such, but merely show a mass of nuclei (Plate XXII. Fig. 6). Sometimes nearly all the living cells of the tube have been cast (Plate XXII. Fig. 6), leaving perhaps one cell or a nucleus or two, attached to the basement membrane.

The lesions of the conducting tubes are of the same character, but more marked than the lesions of the secreting tubes. Where the lumen is filled up by a large cast, or numbers of nuclei (Plate XXII. Figs. 8, 9, 10, 3, $)$, the tube is enormonsly dilated for some part of its length. The débris collected at the end of the kidney tubes is naturally far more than that at the beginning; therefore, at the end, there is more dilatation. Both collecting tubes and secreting tubes have some tendency to shrink away from their base. This condition strongly suggests a wholesale "casting off" of the tubule; but, as can be seen, this is not really the case, for there is no outer ragged edge of protoplasm (Plate XXII. Figs. 8, 9).

On the whole, the glomeruli are very little affected in rabbits, and not at all in guinea-pigs. There is some proliferation of the nuclei of their interstitial tissue, but this is not very general.

The glomerular spaces are somewhat dilated in those cases where dilatation of the whole kidney is very marked, otherwise it is not a promiuent feature. We have found no albumin in the capsule, and the filtration prowers of the glomerulus are probably not impaired.

The glomerular capsules are thickened, but not greatly; and though most of our specimens show one or two altered capsules (Plate XXII. Fig. 7) the great majority are little changed.

The blood vessels are always engorged-sometimes enormouslybut hæmorrhages are very rare. Indeed, they occur in only one or two 
of the animals, and are then slight (guinea-pig 4, rabbit 4). Many leucocytes of various forms are occasionally found in the blood vessels, and are usually associated with round-celled infiltration in other parts of the kidney. In these cases there is also leucocytic infiltration of the liver and control kidney, and this infiltration is far more marked in the liver than in the control kidney. No profound destruction of tissue, therefore, arises from the congestion, for even when the blood vessels do press on neighbouring tubules, there still remain very many unaffected tubules, except in those cases where life persisted for more than one month after operation.

We now come to the question of infiltration by connective tissue cells. This process has scarcely begun in guinea-pig 4, that lived five days; only a few connective tissue cells are to be seen in a thin line between adjacent secreting tubules. The other animals all show (Plate XXII., Figs. 6, 7) varying degrees of infiltration; in some cases the tubes are divided by connective tissue cells, and in others by actual (delicate) connective tissue.

Again in rabbit $B$, which was killed after two days, there is no adventitious connective tissue in the kidney, whereas in rabbit 7 , fifteen days, cells and formed fibrous tissue already permeate the kidney and crush the tubes; this is scarcely more marked in rabbit 6 , twenty-nine days.

In the extreme cases some of the tubules are so crushed as to be obviously useless, but in most cases a very fair proportion of the tubules are still functionally active. The kidney was evidently deformed and constricted in one or two cases. A patchy round-celled infiltration has also been observed in several specimens, though post-mortem no abscesses were discovered, nor was there pyelonephritis, except in one case (guinea-pig 5).

We may therefore agree with $W$. Lindemann in classing the changes in a kidney whose ureter has been ligatured into three stages(1) stage of circulation changes (which we see also in the control kidneys); (2) stage of dilatation of canaliculi; (3) stage of atrophy.

Albarran (Th. doct., 1889) also describes the effects of aseptic ligature and hydronephrosis; and our results agree with his, except that he finds the glomeruli to be more affected than we do. Lindemann also generalises these results thus: "Interstitial changes follow parenchymatous ones, and only after some or many of the canaliculi have degenerated. The changes in the Malpighian bodies may be slight." The condition we describe is one of preliminary uronephrosis, leading to atrophy. We are justified in styling it uronephrosis, because the kidney in the early stages is dilated, but not profoundly degenerated.

The first question that occurred to us was, Are these changes in the kidney on the ligatured side enough to cause death? And if 
not, are there such changes in the control kidney, that the lesions of the two together might cause death?

The last question may be answered at once: Slight changes on the control side exist, but they are not so serious that the kidney cannot act. The secreting tubes are quite healthy, or else they are merely swollen; a few show a tendency to fray at the inner edge (this appearance may be artificial). Their nuclei are nearly universally healthy. In one case (rabbit 6) the protoplasm of opposite sides is joined together by a fine reticulum of precipitated substance; this suggests either the initial stage of a swelling or else a retrogressive change, though we may remember that Castaigne and Rathery consider it due to bad fixation. In guinea-pig 2 the nuclei have followed the swelling inner border of the cell inwards, and are all arranged in the axis of the tube, whose lumen is quite filled up. The conducting tubes do not swell so much. They look quite healthy; they often contain granular matter or casts; but these rarely dilate the tube.

The glomeruli and their capsules show no changes. The blood vessels are usually exceedingly full, and in one or two cases we have seen hæmorrhages, and in one case patchy round-celled infiltration. Proliferation of connective tissue cells is absent. In short, the kidney on the control side presents the appearances of slight congestion and slight compensatory hypertrophy. It is probable that these slight changes in the control kidneys do not sensibly contribute to the death of the animals with one tied ureter. Further, we have found no gross changes in the amount of urine passed until just immediately before death, nor has any dropsy been observed. Therefore, we looked for some other organic change, which, by weakening the general resistance, inight account for death.

Changes were found in the liver of most of the animals in which the liver was preserved, e.g. two guinea-pigs and five of the seven rabbits in which one ureter was tied, and the animal left to die. In the sixth the liver was not preserved. In these specimens the blood vessels are at once seen to be engorged with blood. The capillaries are so full that the adjacent liver cells are compressed, flattened, and look as if they had been "drawn out" (Plate XXII. Fig. 11). Further, the outlines of the cells are no longer sharp and clear, the cell protoplasm being less granular than in the normal cells. Some of the preparations show the presence of fat in the liver cells. Most of the livers show a slight infiltration by round cells. These invade the cells, the intercellular spaces, and the blood vessels (Plate XXII. Figs, 12, 13).

In the livers of the rabbits there sometimes appears to be a distinct increase of connective tissue cells in the portal regions (Plate XXII. Figs. 12, 13). There is no evidence of inflammation round the hepatic veins. 


\section{The Effect of the Ligature of the whole Pedicle and of the Renal Vessels of ONe Kidney.}

I also tied the whole pedicle of the kidney in one rabbit (No. 93), and the artery and vein of one kidney in another (No. 11), in each case making a dorsal incision and bringing the kidney up into the wound. The animals recovered rapidly after the operation, and showed no signs of disease for a very long period; death occurred after sixty-four days in the case of No. 11; and in the case of No. 93 the animal was killed after one hundred and fifty-two days, when its general condition was excellent. In the latter case, at the postmortem, I found that the tied kidney had atrophied almost entirely, and was firmly adherent to the adjacent tissues; indeed, it was merely a small, hard, calcareous mass. In the case of No. 11 the kidney on the tied side was very small, hard, and adherent. Though the kidney structure was still clearly defined, cell demarcations were lost, the nuclei were not to be seen, and the tubes were full of protoplasmic casts. Thus there was no evidence of absorption of kidney substance.

Therefore, we cannot logically hold the absorption of : the destruction products of the kidneys responsible for the death of animals in which one ureter has been tied.

\section{The Effect of Temporary Ligature of one Ureter.}

I also tried, in one animal, the effect of ligaturing the ureter for fourteen days (rabbit $6 \beta$ ).

This was done by opening the abdomen, securing the ureter, and then passing a small sterilised glass rod under it; a figure of eight ligature was then made over the ureter round the ends of the glass rod. By this device I was able to cut the ligature and slip out the glass rod without injuring the ureter, when at a subsequent operation I reopened the abdomen to release the ureter. The animal lost weight at first very rapidly, though the wound was healthy, and no albumin appeared in the urine. When the weight had decreased very considerably ( 215 grms.), I anæsthetised the animal again, and removed the glass rod, finding the ureter still patent, though it was considerably distended above the point of ligature. The abdomen was closed, and the animal made a good recovery. It still lost weight for thirteen days, but then began to gain, and after thirty-five days it was very fat and well. I then killed it (forty-nine days after the first operation). The kidney, the ureter of which had been tied, was partly cirrhosed and atrophied.

In spite, therefore, of considerable cirrhosis and destruction of the kidney, the animal recovered its previous loss of weight, as soon as the way was left free for excretion of toxic constituents of the urine.

This again we may take as an argument for the innocuousness of kidney tissue itself. This I confirmed by the following experiments :-

\section{Effect of Unilateral Nephrectomy, and Subsequent InJECTION OF KiDNEY SUBSTANCE.}

In four rabbits (84 and 79,7 and 28 ) I excised the left kidney by a ventral operation. Each animal lost weight considerably during five days, but in eight 
days was again gaining weight. I now began a series of intraperitoneal injections of freshly macerated rabbit kidney substance; two animals received one-eighth of a kidney, and the other two one-sixteenth; these injections were repeated four times, at intervals of about fourteen days each time; eventually two had received one-half, one, one-quarter, and one, seven-eighths of a kidney. The animals persistently gained in weight, and after seventy days three of then weighed more than they had done originally. They showed no signs of albuminuria. Finally they were killed, and their serum was injected subcutaneously into four other rabbits, without producing any appreciable symptoms.

Incidentally I tested these auto-sera for hæmolytic properties, and found two of them strongly hæmolytic and two non-hæmolytic. In the case of the two latter the injected kidney had been previously washed free of blood. I think that these experiments may be taken as conclusive proof that kidney tissue is not toxic when absorbed into the general organism.

\section{SUMmaRY.}

The experiments just described show that the ligature of one ureter in the rabbit or guinea-pig is followed by death, after a period varying from a few weeks to several months. Death may be preceded by convulsions and Cheyne-Stokes respiration and wasting, but only occasionally by slight albuminuria and never by cedema:

The autopsy shows obvious changes in the kidney, the ureter of which has been tied, slight alterations in the liver, but no alterations in the heart, and, be it noted, only very slight changes, in the other kidney. Ligature of one ureter, therefore, does not produce all the well-known clinical phenomena of kidney disease, nor do the pathological changes in the various organs correspond to those of acute or chronic kidney disease.

How is death then to be explained? Several suppositions present themselves-

1. One may suppose that death is produced by the inability of one kidney to perform the excretory work of two. Against this theory there is the fact that, when one kidney is excised, the other kidney is able to compensate the other for a considerable time, and an animal with one kidney may even gain greatly in weight.

2. Another supposition is, that the internal secretion of one kidney is not sufficient to sustain life, but this is again shown to be fallacious by the fact that animals with one kidney actually gain in weight.

3. One may suppose that death is due to the absorption of $(a)$ the products of the disintegration of the kidney cells of the ligatured ' side, or $(b)$ of the products of the secretion of the ligatured kidney.

The first possibility is rendered very improbable by the fact that there is no evidence to show that absorption of kidney substance produces any noticeable symptoms or pathological changes. I have 
shown that even after the removal of one kidney the injection of large quantities of kidney substance in the nephrectomised animal produces no pathological changes or even noticeable symptoms. Similarly, temporary ligature of the ureter, although it is followed by atrophy of the ligatured kidney, produces no definite symptoms and no pathological appearances. There is no evidence to show, therefore, that kidney substance ever acts as a poison to animals of the same species.

The other hypothesis, however, must now be examined. I have shown that although many of the cells on the ligatured side have disappeared or atrophied, yet the ureter and the pelvis of the kidney are always found dilated with urine. Moreover, the blood supply around the ligatured ureter is not only kept up, but appears to be rather exaggerated. We may assume, therefore, that the secretion of the kidney on the ligatured side is not abolished, and that the toxic constituents of urine are being absorbed from it. The latter circulate through, and act on the various organs of the body before they are finally excreted for good by the healthy kidney. The animal with the tied ureter, therefore, may be compared to a patient suffering from a gradual blocking up of the ureters, as, for instance, by a tumour, and in which symptoms of uræmia set in even before the obstruction has become complete.

I am indebted to the President of the Council, Dr. Armand Ruffer, for many useful suggestions and for advice.

\section{APPENDIX I. ${ }^{1}$}

GUINEA-PIG 1.-Length of life, twenty days.-General aspect.-Great dilatation of the tubes; distinct round-celled infiltration in one or two places round the blood vessels; little excess formation of fibrous tissue; tubular structure not much disturbed but crushed.

Tied Kidnex.-Secreting tubules.-(a) Epithelial cells are mostly swollen, and protoplasm is less granular than in the normal, but nuclei are healthy. In a few, epithelium is breaking away piecemeal. (b) A few contain granular and nucleated débris, leucocytes, and epithelial cells.

Conducting tubes are much dilated. (a) Epithelium mostly healthy, but sometimes frayed or flattened out. The nuclei are mainly healthy, but a few are shrunken and overstained. (b) Cellular and hyaline casts are frequent. Leucocytes are also present with the casts.

Glomeruli are a little squashed and flattened. No albumin or blood in the glomerular spaces. No thickening of capsule.

Blood vessels are full; no hæmorrhages.

Connective tissue.-Slight fibrinous thickening of basement membrane of all the tubes. Slight interstitial growth.

Control KinneY.-General aspect.-The kidney appears quite healthy.

Conducting tubes contain small hyaline and epithelial casts, though not many.

Blood vessels are very full.

"By "tied kidney" is meant the kidney the ureter of which has been tied; by "control kidney" the kidney on the other side. By "length of life" is meant length of life after operation. 
Guinea-PIa 2.-Length of life, twenty-three days.-General aspect of TIED KIDNEY.-Considerable dilatation of tubes throughout. The secreting tubules are crowded together.

Secreting tubules.-Epithelium is swollen; protoplasm is less granular than normal; nuclei are healthy.

Conducting tubules are much dilated. (a) Epithelium is frayed and flattened out. The nuclei are beginning to be deformed and to disintegrate. (b) There are many small hyaline and epithelial casts.

Glomeruli.-(a) Are full of blood, and fill the spaces more than they do in the control kidney. (b) Capsules slightly thickened.

Blood vessels are full; one or two hæmorrhages.

Control KIDNeY.-General aspect.-Very healthy. (a) Epithelial edges slightly frayed. (b) A few epithelial and hyaline casts.

Blood vessels are very full.

Guinea-pig 3.-Length of life, twenty-three days.-TiEd KIDnex.-General aspect.-Cortex is invaded by strands of connective tissue, and connective tissue cells, which largely destroy tubular arrangement; also there are numerous islands of round-celled infiltration.

Secreting tubules.-Epithelium is swollen and compressed. Nuclei show every stage of degeneration, from darkly staining to almost colourless masses; they are also to be seen breaking away.

Conducting tubules.-(a) Epithelium is flattened and breaking away. Nuclei are breaking down and degenerating. (b) There are enormous epithelial and hyaline casts dilating these tubules.

Glomeruli are infiltrated with connective tissue cells. Some of them are flattened and their spaces much dilated. Some capsules are thickened.

Blood vessels are engorged.

Connective tissue cells, or fibrous strands, pervade and destroy the symmetry of the whole kidney.

ControI. Kidney.-General aspect healthy.

Secreting tubules are practically entirely healthy.

Conducting tubules are healthy.

Blood vessels are engorged.

Guinea-pig 4.-Length of life, five days. - General aspect.-General arrangement is not disturbed. The secreting tubules are swollen, the blood vessels engorged. Albuminous, hyaline, and epithelial casts are plentiful.

Secreting tubules. - (a) Epithelium is-(1) swollen, (2) beginning to disintegrate. Nuclei also show a slight tendency to break down. (b) Albuminous and epithelial casts are present.

Conducting tubules.-(a) Epithelium is-(1) disintegrating, (2) breaking away, (3) flattened out by (b) large epithelial and albuminous casts which dilate the tubules; the nuclei of the tubule cells are much diseased.

Glomeruli are engorged with blood; supporting connective tissue is much increased; the glomerular spaces are not dilated; capsules not thickened.

Blood vessels are enormously engorged. A few hæmorrhages.

Connective tissue.-There is a slight general infiltration by connective tissue cells.

Control Kidney.-General aspect is very healthy. There is a faint increase of connective tissue cells formation and some casts.

The secreting tubules are very healthy, save that in places the epithelium is a little swollen.

The conducting tubules show-(a) (1) swollen epithelium, (2) disintegrating epithelium, (3) epithelium flattened out by $(b)$ large cellular and hyaline casts.

The glomeruli are full of blood, and their supporting connective tissue is increased. Capsules are a little thickened.

19—J., of patr.-rou. $x$. 
The blood vessels are full.

Connective tissue.-There is a general very slight sprinkling of connective tissue cells between the tubules.

Guinka-Pig 5.-Length of life, twenty-one days.-Post-mortem result.-On the tied side the ureter was dilated; the kidney very slightly dilated. Pyelonephritis. The liver and suprarenals were red, hyperæmic, and soft. The heart was flabby.

Microscopic examination.-TIED KIDNeY.-General aspect.-Tubular structure is almost quite obscured by a dense general fibrosis. A few glands containing hyaline and nucleated epithelial casts are still distinguishable, but they are extremely degenerated. There are several areas of round-celled infiltration.

Secreting tulules.--The epithelium shows-(1) masses of swollen protoplasm, containing more or less diseased nuclei and many healthy nuclei, arranged normally; (2) disintegrating protoplasm with distorted nuclei.

Conducting tubules. - (a)-(1) Some quite healthy tubules; (2) tubules with flattened epithelium and diseased nuclei; (3) tubules with swollen disintegrating protoplasm and diseased nuclei. $(b)$ There are nucleated and hyaline casts. But these tubules are mostly entirely opened by connective tissue cells.

The glomeruli are full. There is a tendency to great thickening of their capsules.

The blood vessels are very full.

Connective tissue cells pervade the whole kidney in masses; but there is little actual fibrosis yet.

Control Kidney.-General aspect.-The whole kidney slightly swollen and full of blood.

Secreting tubules.-These are all slightly swollen, but striation still shows well. In a few the epithelium is beginning to disintegrate.

Conducting tubules.-(a) Epithelium is swollen and beginning to disintegrate; some of the nuclei are distorted and overstained. (b) There are large epithelial and hyaline casts.

The glomeruli are not altered.

The blood vessels are full.

Liver:-Blood vessels are enormously engorged, so that they force apart the liver cells and flatten them out. The demarcation lines of the cells are indistinct. There is infiltration of small round cells in many places between the liver cells, and in some places these mononuclear cells are full of blood pigment.

Guinea-PIG 6.-Length of life, twenty-three days. - Post-mortem. - The ureter on the tied side was dilated, the kidney only slightly so, but white. The control kidney was normal. The suprarenal capsule of the tied side was redder than that of the control side. The liver was red, soft, and hyperæmic. The heart was flabby.

TIED KIDNEY.-General aspect.-Fxtreme dilatation of the conducting tubes and glomerular spaces; considerable excess of connective tissue cells.

The secreting tubules. - (a)-(1) The epithelial cells have lost their specific appearance and resemble cells of Henle's loops; (2) they are much swollen, and their protoplasm is disintegrating; their nuclei are diseased, and are breaking up and falling away. (b) Nuclear and albuminous débris are to be seen in some tubules.

The conducting tubules.-(a)-(I) The epithelium is healthy, though flattened by the general dilatation; (2) the protoplasm is disintegrating, and barely supports a diseased or healthy nucleus; (3) the protoplasm is swollen and vacuolated. (b) There are hyaline and epithelial casts, also blood corpuscles and leucocytes. 
The glomeruli are altered, thickening of supporting tissues. Capsules are much thickened.

The blood vessels are full.

Connective tissue cells.-Between all the tubes is a marked layer of connective tissue cells.

ConTroL KIDNEY.-General aspect is very healthy, except that it is gorged with blood. There is a slight tendency to swelling and disintegration in both the secreting and conducting tubules; here and there a tube is seen in which cells are beginning to be cast off.

The blood vessels are strikingly engorged. A few slight hæmorrhages.

Liver.-Blood vessels are very much engorged, and the small capillaries press on the liver cells, so that they have lost their characteristic shape and their definite outlines. There are leucocytes in some of the blood vessels and also scattered about among the liver cells. Here and there among the liver cells the oval nuclei of connective tissue cells are to be seen also. There are some few hæmorrhages also.

The heart.-Nothing abnormal to be seen.

RABBIT 1.-Length of life, fifty-three days.-Post-mortem.-(Death in convulsions, Coccidia.) Ureter and kidney pelvis of the tied side very much dilated; kidney is white. Control kidney is also large, but less so. Liver is very hyperæmic. The suprarenal capsules are normal.

TIED KidneY.-General aspect.-The tubules are surrounded by dense fibrous tissue; many of them are extremely dilated.

Secreting tubules.-(a)-(1) The cell outlines are lost, but nuclei are healthy; protoplasm is not granular. (2) The protoplasm is vacuolated and disintegrating, and the nuclei are deformed and undifferentiated. The tubules are all crushed together by fibrous tissue.

Conducting tubules.- $(a)$ Generally speaking, the epithelium is degenerating, as in the secreting tubules. (b) Casts of all sorts are present, and they may flatten out the epithelium of the tube that contains them, where it still persists.

The glomeruli are very full, and their connective tissue is increased. Capsules are fibrous.

The blood vessels are very full.

Connective tissue. - Vide above.

Control Kidney.-Secreting tubules are very healthy.

Conducting tubules.- (a) Slight tendency to disintegration of protoplasm. (b) A few small hyaline casts.

The blood vessels very full.

The liver.-Most of the lobules are surrounded by a thick branching strand of connective tissue. The cells are flattened by engorged capillaries, and they also contain fat granules (Flemming fixed specimens).

RABBIT 2.-Length of life, sixty-three days.-Post-mortem.-Ureter and kidney of the tied side much distended. When emptied, the kidney was flabby. Capsule easily detachable. Control kidney was slightly hyperæmic. Liver very congested. Other organs normal.

TIED KIDNEY.-General aspect.-Much reduced in size and very fibrous. Continuous connective tissue, in more or less tubular form, replaced the gland tubes. Between the strands a few masses of protoplasm were seen, which contain healthy and degenerated nuclei.

Secreting tubules.-Infiltrated by connective tissue cells.

Conducting tubules dilated or compressed, and surrounded by thick connective tissue. (a)-(1) Epithelium fairly healthy, slightly flattened; (2) epithelium is breaking away; nuclei are degenerating. (b) Hyaline casts and protoplasmic shrews are common. 
Glomeruli. - Much infiltrated by connective tissue cells; capsules thickened.

Blood vessels not very full.

Connective tissue thickly permeates the whole structure.

Control Kidney.-General aspect.- Slight general changes; no adventitious connective tissue. No hyaline casts.

Secreting tubules. - (a) Very slightly swollen. (b) Slight tendency for the protoplasm and a few healthy nuclei to break away.

Conducting tubules-(a) Show similar changes. (b) In a few tubules are nucleated débris, and in one or two are red blood corpuscles.

Blood vessels. - Very full, a few tiny hæmorrhages.

Liver. - Most of the lobules are more or less surrounded by thick branching strands of connective tissue cells. The blood vessels are so full that the intercellular capillaries press on adjacent cells and flatten them out and deform them. The individual cells have a healthy granular protoplasm and healthy nuclei. Scattered among the cells and in the blood vessels are many healthy leucocytes.

RABBiт 3.-Length of life, seventy-nine days.-A few hours before death, paralysis of posterior limbs and forced respiration. Post-mortem.--Ureter of the tied side was dilated. Kidney of the tied side was dilated, white, and sclerous. Control kidney was larger and hyperæmic. Capsule easily detachable. Liver hyperæmic. Other organs were normal.

TIED KIDNEY.-General aspect.-Excessively fibrous and infiltrated by connective tissue cells. Scarcely any glandular substance visible. Several foci of round cells. No dilatation of tubules.

Secreting tubules. - Surrounded and destroyed by fibrous tissue. $(a)-(1)$ Epithelium crushed together, a few nuclei (some degenerating) only visible; (2) epithelium very swollen and breaking down. (3) Epithelium disappeared and lumen occupied by a hyaline cast.

Conducting tubules.-Much disturbed by fibrous tissue and very few remaining. (a)-(1) Epithelium healthy, slightly flattened; (2) epithelium breaking away, and its nuclei becoming deformed and broken. (b) Hyaline casts and cellular débris plentiful.

Glomeruli are infiltrated by connective tissue cells, and their capsules are very thick.

Blood vessels not distinguishable.

Connective tissue cells pervade and destroy the whole kidney.

Control Kidney._General aspect._-Early slight degenerative changes; some hyaline casts; no adventitious connective tissue.

Secreting tubules. - Mostly healthy, but some are swollen; their protoplasm tends to "fray"; and cell outlines are not clear. Striated border is visible in some cases. Nuclei are mainly healthy.

Conducting tubules.-(a)-(1) Show similar changes; (2) a few nuclei are breaking down; (3) epithelium is flattened out. (b) Hyaline casts and epithelial débris are common.

Blood vessels are full.

Liver.-(Saffranin stain). - The lobules are nearly all marked off by strands of connective tissue cells, of varying thicknesses and extents. The blood vessels are very full, and the liver cells are thinned out and compressed by them. Leucocytes are freely invading the lobules. The cell outlines are vague.

Heart.-The cells stain normally, branch normally, and are not split about. Nuclei are healthy.

RABBIT $4(\mathrm{P})$.- - Length of life, one hundred days.-Post-mortem.-Ureter of the tied side adherent to the intestine, and dilated. Tied kidney dilated and thin-walled, adhesions all over. Control kidney adherent, large and hard. Liver hyperæmic. Heart normal. 
TIED Krdney (Iron-hæmatoxylin fuchsin).-General aspect.-Cortex is shrunken and infiltrated by connective tissue cells and organised fibrous tissue, which largely replaces the tubules and destroys them. No dilatation of tubules. In fact, all appearances of granular contracted kidney.

Secreting tubules.-(a)-(1) Epithelium swollen and disintegrating; nuclei in various stages of degeneration, swollen and dark; fatty degeneration is evident.

Conducting tubules.-(a)-(1) In a few tubes, epithelium flattened, nuclei healthy; (2) epithelium swollen and disintegrating; (3) protoplasm almost gone, nuclei profoundly diseased. (b) Casts are profuse, both hyaline and epithelial.

Glomeruli are infiltrated by connective tissue cells and fibrous in places. Capsules are fibrous.

Blood vessels.-Very full, and hæmorrhages are to be seen in places. Leucocytes in some quantity.

Connective tissue surrounds all the tubules, and connective tissue cells invade many tubules.

Control Kidney.-General aspect.-Very healthy.

Secreting tubules.-Mostly normal, but a few are swollen and breaking down at the inner border, and losing striated effect; a few nuclei show degenerative changes.

Conducting tubules.- -Show the same occasional slight changes.

Blood vessels are engorged; some leucocytes.

Liver.-The lobules are very markedly separated from each other by thick strands of connective tissue cells. The blood vessels are engorged, and they deform the adjacent liver cells. There are many leucocytes in the blood vessels and capillary spaces. The flattened liver cells are in many parts quite healthy, but in others their outlines are indistinct. The nuclei are healthy. No fat is visible. The capsule of Glisson is not thickened.

Heart.-Nothing abnormal found.

RABBIT 5 (Q.).-Length of life, fifty-five days.-TIED KidNEx.-General aspect. $-\Lambda$ honey-comb of connective tissue cells and fibrous tissue, filled by deformed, degenerated, and dilated tubes, which contains casts.

Secreting tubules.-(a)-(1) Epithelium degenerating, and losing specific character; nuclei, darkish and beginning to be deformed. (2) Epithelium quite gone. Tube full of nuclei and protoplasmic débris.

Conducting tubules.-Much dilated. (a)-(1) Epithelium flattened; (2) epithelium breaking down and nuclei degenerating. (b) Casts, hyaline and nuclear, are plentiful.

Glomeruli are permeated by connective tissue cells. Glomerular spaces are dilated. Capsules are fibrous and thickened.

Blood vessels are fairly full of blood.

Connective tissue is the main feature of the kidney; it encircles each tube, blood vessel, and glomerulus.

Control KIDNEY.-Fairly healthy, but some dilatation of conducting tubes; early degenerative changes.

Secreting tubes.-(a)-(1) Many are quite healthy; (2) some are swollen and tend to break down; (3) a few contain nucleated débris.

Conducting tubes. - (a) Are all slightly dilated-(1) in some the epithelium is flattened; (2) in some the epithelium is beginning to break down; most of the nuclei are healthy, but a few are breaking down. (b) There are many hyaline, nucleated, and blood casts.

Glomerular spaces are dilated.

Blood vessels are engorged.

Heart. - Nothing abnormal.

RABBIT $6(\mathrm{R})$.-Length of life, tienty-nine dayj.-TIED KInNEY.-General 
aspect.-Warked dilatation of the conducting tubes; some fibrosis; casts; general disorganisation.

Secreting tubules.-(a) Swollen; no striation left; tendency to vesicular degeneration; nuclei stain badly, and are beginning to be deformed.

Conducting tubules.-Enormously dilated and flattened. (a)-(1) Protoplasm is shredding away and nuclei are disintegrating; (2) protoplasm is swollen; nuclei mainly diseased. (b) Some epithelial and hyaline casts and blood casts.

Glomeruli.-Connective tissue framework very apparent; capsule thickened ; capsular space dilated.

Blood vessets.-Fairly full ; some hæmorrhages into tubes.

Connective tissue.-Fibrous tissue pervades the whole kidney; here and there is a conglomeration of connective tissue cells.

Control Kidney.-Very healthy. Slight dilatation of the conducting tubes, and some slight hæmorrhages into the tubes. Slight degenerative changes in the conducting lubules and secreting tubules, where protoplasm is breaking away into the lumen in the form of balls.

Liver.-(Iron-hæmatoxylin). - Shows a marked tendency to formation of fibrous tissue between all the lobules; quite a thick strand surrounds some lobules; while in others there is merely a faint thin fibrous band. Here the blood vessels are very full, and the capillaries have deformed and hollowed out the liver cells. There are evidences of fatty degeneration.

RABBIY 7 (S).-Killed after fifteen days.--TIED KIDNEY.-General aspert. -Considerable dilatation of tubules, whose epithelium is fairly intact.

Secreting tubules.- (a)-(1) Their epithelium has lost its specific characters, and is indistinguishable from that of conducting tubes, except (2) when it is very swollen, and filled up by its own swollen nuclei. No albuminous balls.

Conducting tubes.-(a)-(1) Epithelium is flattened and nuclei are healthy, even though slightly deformed ; (2) epithelium is "ragging away," and nuclei are losing their staining properties. (b) Hyaline casts and nucleated débris are common.

Glomeruli.-Capsule is slightly thickened.

Blood vessels.-Very full; some hæmorrhages; leucocytes in the blood vessels.

Connective tissue. - Connective tissue cells permeate the intertubular regions, and there is very much fibrous tissue pushing aside and replacing the tubes.

CoNTrou Kidner.-Early slight degenerative changes in the tubules; no adventitious connective tissue.

Secreting tubules.-Are slightly swollen; no albuminous balls; slight tendency to break down.

Conducting tubes.-Are also slightly swollen, and trabecula are forming right across the lumen.

Liver:-Cells are perfectly clear; each canaliculus like a diagram; no adventitious connective tissue ; blood vessels not very full.

RABBit $8(\mathrm{~T})$.- Killed after two days.-TiEd KIDNey.-Very early degenerative changes. No adventitious connective tissue.

Secreting tubes. - Are swollen, but retain striation. Nuclei healthy; some are disintegrating; no albuminous balls.

Conducting tubules. - Epithelium very healthy; some hyaline casts; a peculiar vesicular effect in the lumen of many tubes.

Blood vessels very full; a few hæmorrhages.

RABBIT 9.-Length of life, twenty-eight days.-The left ureter was tied on Jan. 4, 1904; weight, 1100 grms.-Jan. 15.-Doing well. Jan. 29.-Weight 1005 ; urine albuminous; not eating. Feb. 1.-Animal died. 
Post-mortem.-The left kidney was large and full of urine. The cortex was hyperæmic. The ureter was dilated. The right kidney was slightly enlarged. The liver was hyperæmic. There were adhesions of the abdominal wound to the intestines, but no serious stricture resulted.

RABBir 14.-Length of life, 110 days. - The left ureter was tied on May 17, 1903 ; weight, 1104 grms. During the next three months the weight increased slowly, being 1150 grms. On August 17 the animal was quite healthy, the urine was normal. On August 17 the abdomen was reopened, and the left ureter was found to be tortmous and hypertrophied. On August 24 the animal was not eating, the weight was 1035 grms., and the urine was albuminous. On $\Lambda$ ugust 29 weight was 1000 grms., and the urine was scanty and albuminous. On September 4 the animal was lying on one side breathing irregularly; it was conscious. There were no convulsions; there was incontinence of fæces. At 11.15 a.m. the animal died.

Post-mortem.- The left kidney was found to be merely a dilated sac, full of altered urine, thick, dark, and creamy. The left ureter was dilated. The right kidney was large and hypertrophied. The urine in the bladder was slightly albuminous. The liver was red and hyperæmic. The heart was large and full of blood. The spleen and suprarenals were normal.

Rabit A.-Length of life, two days.-Both ureters tied.-(Saffranin).General aspect.-Extreme dilatation of all the tubes and glomerular capsules, "skeleton" effect; early tubular degenerative changes; no adventitious connective tissue.

Secreting tubes.-(a) Swelling (slight) of the cells, but outlines are still quite clear; slight shedding of protoplasm, but no albuminous balls; a good deal of vesicular degeneration.

Conducting tubes.-(a) Are all slightly swollen (nuclei healthy). In some places protoplasm of opposite sides is so swollen that it meets in the centre of the lumen. Vesicular degeneration. (b) No true casts, but some epithelial débris.

Glomeruli.-Spaces are much dilated.

Blood vessels very full and dilated.

Liver.-There is a marked interlobular deposit of connective tissue cells round most of the lobules. In the blood vessels (which are engorged) are many leucocytes, and these are also found among the liver cells, which are somewhat deformed by the engorged capillaries among them.

RABBIT B.-Length of life, two days.-Both ureters tied.-KIDNEY.-. General aspect.-The kidney is as dilated as in Rabbit A. There are early degenerative changes, without formation of adventitious connective tissue. A marked feature is the tendency to formation of albuminous balls by the protoplasm as it breaks up.

Secreting tubes.-(a) Slight general swelling and breaking down of protoplasm; nuclei are healthy.

Conducting tubes. - (a)-(1) Slightly swollen; (2) breaking away, in "balls," of protoplasm. Lumen full of "vesicular" débris. Nuclei mainly healthy.

Glomeruli.-In a few capsules there is albumin.

Blood vessels are engorged.

Liver.-There is a slight universal tendency to interlobular fibrosis. The engorged blood vessels flatten out the liver cells, and also contain leucocytes. These latter are to be found scattered about among the liver cells.

RABBiT 11.-Length of life, sixty-four days.-Artery and vein of one lidney tied, through a dorsal incision. - Weight, 1545 grms. on July 30, 1903. Urine normal.

July 31.-The animal was very active, and weighed 1540 grms. Tempera- 
ture, $39^{\circ} \cdot 2$ C. Aug. 2.-Temperature, $37^{\circ} \cdot 2$ C. Aug. 4.-Temperature, $37^{\circ} \cdot 2$ C. The urine was very albuminous. Aug. 5.-Temperature, $38^{\circ} \cdot 6 \mathrm{C}$. Aug. 25.-Weight, 1350 grms. The general condition was good. Aug. 29.Weight, 1357 grms. Sept. 5.-Weight, 1317 grms. Sept. 15.-Weight, 1397 grms. The urine was scanty and rather albuminous. Sept. 24.Weight, 1302 grms. The animal getting weak. The urine was albuminous. Oct. 2.-Weight, 1105 grms. The animal died.

Post-mortem. - The left kidney was found to be very small, very hard, and quite adherent to surrounding tissues. There was no pus or contained urine. The left ureter and efferent vein were very small. The right kidney was very large, soft, and hypertrophied. The liver was large and hyperæmic. The heart was large and engorged. The spleen and suprarenals were normal.

$\mathrm{R}_{\mathrm{ABBIT}}$ 93.-Killed after 152 days.-Pedicle of one kidney tied through a dorsal incision.-Weight, 1330 grms. on October 26, 1903 . Urine normal.

Oct. 31.-Weight, 1220 grms. The animal is feeding well. Two stitches through the skin of the dorsal wound have given way. Nov. 7.--The animal is quite well. Jan. 16, 1904.-The animal is perfectly well. Urine normal. Weight, 1415 grms. March 26.-The animal is very well and strong. Weight, 1420 grms. He was killed on this day.

Post-mortem. - The left kidney was found to be absolutely hard and calcareous, and to be covered by layers of connective tissue; it was small, and its form was scarcely recognisable. The right kidney was in no way remarkable.

RABвIт $6 \beta$.-Killed after forty-nine days.-One ureter temporarily occluded. -Weight, 1550 grms. on January 19, when the abdomen was opened and a small sterilised glass rod was slipped under the left ureter; a figure of 8 thread occluded the ureter. The abdomen was then closed.

Jan. 25.-The wound had healed. Weight, 1505 grms. Jan. 27.Weight, 1500 grms. No albumin in urine. Jan. 28. - Weight, 1350 grms. Jan. 29. -Weight, 1350 grms. Feb. 1. -Weight, 1285 grms. Feb. 2.Weight, 1290 grms. The abdominal wound was reopened, and the glass rod was removed without injury to the ureter. The ureter was quite patent; urine flowed along it, as soon as the ligature and rod were removed. The wound was reclosed. Feb. 6.-Weight, 1120 grms. Feb. 8.-Weight, 1001 grms. Feb. 13.-Weight, 1000 grms. Feb. 15.-Weight, 1006 grms. Feb. 18. - Weight, 1116 grms. Feb. 24.-Weight, 1350 grms. March 4.Weight, 1340 grms. March 8.--Weight, 1350 grms. No albumin in urine. As the animal was now again in excellent condition, gaining weight daily, and showing no signs of illness, it was killed.

Post-mortem.-The left kidney was 1.60 grms. less heavy than the right; it was markedly pale, and the cortex was much contracted and cirrhosed.

Rabirs 84 AND 79. - In each on February 10, 1903, the left kidney was excised through a ventral incision. The wound was then closed, and allowed to heal. When the animals were again well and strong they were injected with one-sixteenth and one-eighth of a freshly macerated rabbit's kidney, intraperitoneally. These injections were repeated at varying intervals, and the general condition of the animal and his urine was observed.

As the animals, after four injections, were evidently thriving and gaining in weight, they were killed and their serum was tested for hæmolytic properties, with rabbit's red corpuscles which had been three times centrifugalised with physiological salt solution. The sera were hæmolytic.

RabBit 84.-Feb. 10.-Weight, 1305 grms. Left kidney excised. Feb. 13.-Weight, 1130 grms. Feb. 15.-Weight, 1070 grms. Feb. 18.-Weight, 1090 grms. Feb. 19.-Weight, 1060 grms. Injected with one-sixteenth of a healthy kidney. Feb. 20.-Weight, 1070 grms. Temperature, $39^{\circ} \cdot 4 \mathrm{C}$. 
Feb. 22.-Weight, 1110 grms. No albuminuria. Feb. 24.-Weight, 1090 grms. March 4.-Weight, 1165 grms. Narch 11.-Weight, 1210 grms. Injected one-sixteenth healthy rabbit kidney. March 24.-Weight, 1360 grms. No albuminuria. April 2.-Weight, —- grms. Injected onesixteenth healthy kidney. April 5.-Weight, $1380 \mathrm{grms}$. April 7.-Weight, 1345 grms. April 9.-Weight, 1370 grms. April 12.-Weight, 1340 grms. April 15.-Weight, 1350 grms. April 18.-Weight, 1347 grms. Injected one-sixteenth healthy kidney. April 21.-Weight, 1358 grms. Killed; serum collected.

RABBIT 79.-Feb. 11.-Weight, 1100 grms. Left kidney excised. Feb. 13.-Weight, 980 grms. Feb. 15.-Weight, 890 grms. Feb. 18.-Weight, 995 grms. Feb. 19.-Weight, 1020 grms. Injected one-eighth healthy kidney. Feb. 20.-Weight, 1050 grms. Temperature, $39^{\circ} \cdot 6$ C. Feb. 22.Weight, 1090 grms. Feb. 24.-Weight, 1120 grms. March 4.-Weight, 1140 grms. March 1i.-Weight, 1145 grms. Injected one-eighth healthy kidney. March 24.-Weight, 1160 grms. No albuminuria. April 2.Weight, 1165 grms. Injected one-eighth healthy kidney. April 5.-Weight, 1160 grms. April 7.-Weight, 1145 grms. April 9.-Weight, $1180 \mathrm{grms}$. April 12.-Weight, 1135 grms. April 15.-Weight, 1175 grms. April 18.Weight, 1167 grms. Injected one-eighth healthy kidney. April 21.Weight, 1155 grms. Killed; serum collected:

The sera were tested for hæmolytic properties, and in each the result was the same.

RABBITS 7 AND 28. - In each of these animals the left kidncy was excised, one through a ventral and one through a dorsal incision. When the wounds had healed, and the animals were beginning to regain weight, they were injected with varying quantities of macerated rabbit's kidney, from which the blood had been well washed out, at intervals of about six days. The animals continued to thrive, and were ultimately killed when they had received onehalf and seven-eighths of a rabbit's kidney respectively. Their sera were not found to be hæmolytic, as in the previous two cases.

RABbit 7.-May 16.-Weight, 1320 grms. Left kidney excised. May 18.-Weight, 1310 grms. May 20.-Weight, 1365 grms. May 21.-Weight, 1220 grms. May 23.-Weight, 1250 grms. May 24. -Weight, 1250 grms. Injected with one-eighth of a washed healthy kidney. May 25.-Weight, 1235 grms. May 27.-Weight, 1275 grms. May 30.-Weight, 1200 grms. May 31.-Weight, 1175 grms. Injected with one-eighth of a washed healthy kidney. June 3.-Weight, 1140 grms. June 7.-Weight, 1107 grms. No albumin in urine. June 8.-Injected with one-quarter of a healthy washed kidney. June 21.-Weight, 1105 grms. June 22.-Weight, 1150 grms. The animal was killed, and its serum was tested for hæmolytic properties with rabbits' red corpuscles which had been washed in physiological salt solution, as in the previous two animals. No hæmolysis occurred.

RABBiT 28.-May 20.-Weight, 1355 grms. Left kidney was excised through a dorsal incision. May 21.-Weight, $1320 \mathrm{grms}$. May 24.-Weight, 1365 grms. Injected with one-sixteenth of a healthy washed kidney. May 25.-Weight, 1395. grms. May 27.-Weight, 1355 grms. May 30.-Weight, 1300 grms. May 31. - Weight, 1310 grms. Injected with one-sixteenth of a healthy washed kidney. June 3.-Weight, 1367 grms. June 7.-Weight, 1400 grms. No albumin in urine. June 8.-One-fourth of a healthy washed kidney injected. June 21.-Weight, $1370 \mathrm{grms}$. June 22.-Weight, 1410 grms. June 23.-Weight, 1370 grms. One-fourth of a healthy washed kidney injected. June 28.-Weight, 1410 grms. July 8.-Weight, 1385 grms. Injected with one-fourth of a healthy washed kidney. July 11.Weight, 1415 grms. July 13.-Weight, 1390 grms. The animal was killed 
on that day, and its serum was tested as in the other three animals; no hæmolytic properties were discovered.

\begin{tabular}{|c|c|c|c|c|c|c|}
\hline & Serum. & $\begin{array}{l}\text { Physiological Salt } \\
\text { Solution. }\end{array}$ & Rabbit's Blood. & \multicolumn{3}{|c|}{ Result. } \\
\hline Tube 1. & 10 drops. & 30 drops. & 2 drops. & \multicolumn{3}{|c|}{$\begin{array}{l}\text { In twenty-four hours hæmo- } \\
\text { lysis nearly complete. }\end{array}$} \\
\hline, 2 & 20 & 20 & , & ," & ", & complote. \\
\hline ", 3. & 30, & $10 "$, & ", & ,", & , & , \\
\hline , 4. & 35, & $5 \quad$, & ," & ," & ," & ," \\
\hline
\end{tabular}

\section{APPENDIX II.}

\section{Methods of Fixing and Staining Employed.}

\section{A. Fixing in Flemming's Solution.}

1. Immersion of very small pieces in Flemming's solution for twenty-four hours.

2. Washing in ruming water, twenty-four hours.

3. Immersion in 30 per cent. alcohol, twenty-four hours.

4. " 60 , , twenty-four hours.

5. " $\quad 90 \quad " \quad, \quad$ twenty-four hours and sometimes

6. $\quad$ chloroform, twenty-four hours.

7. " $"$ and a mixture of equal parts hard and soft

paraffin, twenty-four hours, at $56^{\circ} \mathrm{C}$.

8. " " and a mixture of equal parts hard and soft

9. Embedding in a mixture of hard and soft paraffin.

10. After section, the sections were fixed to the slide by preservation for twelve hours at $37^{\circ} \mathrm{C}$.

1. Paraffin was removed by-

(1) Ten minutes immersion in chloroform.

(2) Ten " "

(3) Ten ", " " water.

(a) Staining in Iron-Homatoxylin.

2. Immersion of slides in Heidenhain's iron-hæmatoxylin stain twenty-four hours.

3. The sections were washed in water until they were just black.

4. " " immersed in acid-fuchsin solution for five to ten minutes.

5 . " " washed in water, and three successive baths of alcohol, five minutes.

6 . " " dehydrated with xylol, ten minutes.

7. " " " mounted in Canada balsam.

(b) Staining in Saturated Saffranin.

2. Immersion of slides in saffranin ten to fifteen minutes.

3. Water, until a deepish pink colour remained. 


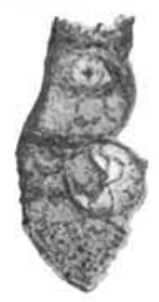

FIG. 1.


Fig. 7 .

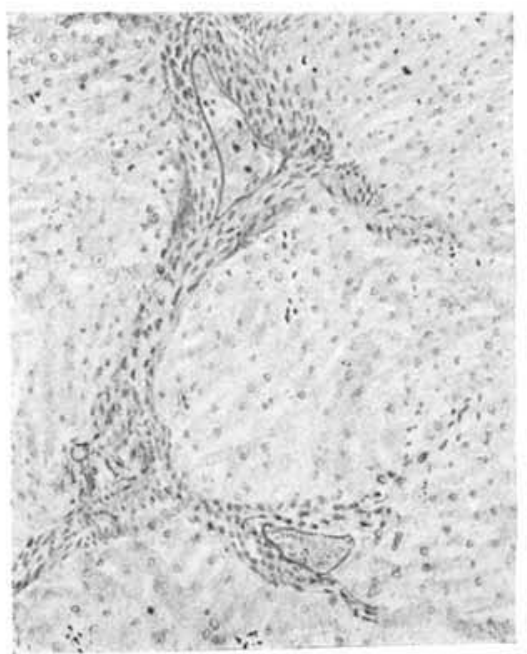

Fic. 13.

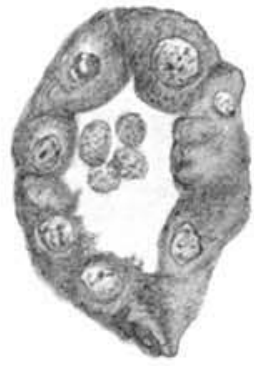

Fic. 2.



Fig. 3.



Fig. 6 .



Fig, 12.



Fig. 11.
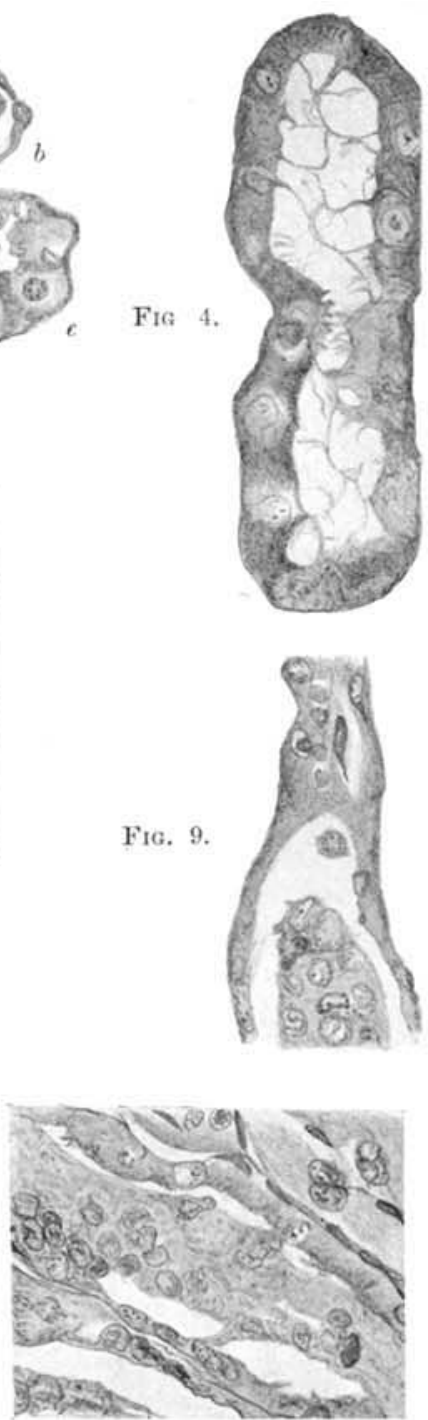

FIG. 10.



Fic. 8 . 
4. Three successive alcohol baths, five minutes each.

5. Xylol, ten minutes.

6. Canada balsam.

\section{B. Fixing in Saturated Sublimate Solution.}

1. Small pieces were immersed for twenty-four hours in saturated sublimate.

2. They were washed in running water for twenty-four hours.

Processes- 3 to 10 for fixing, and (1) and (2) for removing paraffin, as above; but to remove the sublimate-(3) The sections were immersed in iodine solution until red brown. (4) The sections were washed in water until colourless. (5) Then the sections were

6. Water, until violet blue. stained in hæmatoxylin solution (freshly filtered), ten minutes.

7. Eosin, until reddish.

8. Water, one or two seconds.

9. Three successive alcohol baths, ten minutes.

10. Xylol, Canada balsam.

Or sometimes 7 and 8 were omitted and only hæmatoxylin used.

, $\quad 7 \quad 7$ instead of eosin, acid-fuchsin was employed.

\section{LITERATURE.}

Nefediefr . . . . . Ann. de l'Inst. Pasteur, Paris, 1901, tome xv. p. 17.

Albarran and Bhrnamd . Arch. de méd. expér et l'anat. path., Paris, 1903, tome xv. p. 13.

Pearce . . . . . . Univ. of Pennsyl. Med. Bull., Philadelphia, 1903.

Castaigne and Ratheny . Compt. rend. Soc. de Biol., Paris, 1902, tome liv. p. 653.

Lindemann . . . . . Centralbl. f. allg. Path. u. path. Anat., Jena, 1895, Bd. vi. S. 184.

Bradford . . . . . Trans. Path. Soc. London, 1898, vol. xlix. p. 169.

Lazarus Barlow . . . " "Manual of General Pathology," London, 1898.

Guron and Albarran . Arch. de méd. expér. et d'anat. path., Paris, 1890, tome ii. p. 181.

Ebstern . . . . . Vide Charrin, Bouchard's "Traité de pathologie générale," Paris, 1900, tome iii. p. 831.

\section{DESCRIPTION OF PLATE XXII.}

(Drawn on the table with camera lucida.)

FIc. 1-Rabbit B.-Section of secreting tubule.-Showing swelling and disintegration of epithelium and loss of granular texture. ( $\times 350$.

FIG. 2-Rabbit B.-Section of secreting tubute.-Granular balls of protoplasm in centre of lumen; some cells have lost their nuclei; some uuclei show nucleoli, others have lost their differentiation. ( $\times 350$.)

FIG. 3-Rabbit P. - Section of secreting glands-

( $a$ and $e$ ) The epithelium shows fatty degeneration; the cells have coalesced, and are breaking down in to the lumen.

(b) The lumen is distended by a large cellular cast.

(c) The lumen contains a cast ; the epithelial cells have all disappeared from the basal menbrane.

(d) The nuclei are intensely degenerated; they are breaking up, losing their nucleoli, and overstaining. ( $\times 350$. 
FIG. 4-Rabbit B. - Section of secreting tubule. - The epithelium is breaking up, and losing its striated effect; the nuclei of many cells are lost, while in other cells they are degenerating and will not stain. $(\times 350$.

Fit. 5-Rabbit B.-Scction of secreting gland.-The protoplasn is losing its glandular character; the nuclei are bursting out of the cells; and in the lumen cast away nucleated cells are to be seen. $(\times 350$.

FIG. 6-Rabbit P. - Section of ticd kidney, showing marked cirrhosis. - The epithelium of the secreting tubules has lost its granular character, and is swollen; in some tubes it has completely disappeared; in others the lumen is filled with albuminous casts. $(\times 350$.

FIG. 7-Rabbit 1.-Section of tied kidncy, showing even more marked cirrhosis. $(\times 100$.

FIG. 8-Guinea-Pig 4.-Section of tied kidney, showing the collecting tubules enormously dilated by masses of cast-off epithelial cells. $(\times 100$.

FIG. 9-Guinea-Pig 4.-Idem. ( $\times$ 350.)

Fig. 10-Guinea-Pig 4.-Section of control kidney, showing epithelial cast dilating conducting tubule. $(\times 350$.

FIG. 11-Guinea-Pig 6.-Section of liver, showing the liver cells flattened out by blood corpuscles. $(\times 350$.

FIG. 12-Rabbit 3.-Section of liver, showing connective tissue cells in the portal spaces, round cells between the liver cells, and lack of demarcation between individual liver cells. $(x$ 100.)

Frg. 13-Rabbit 2.--Itlem. ( × 100.) 